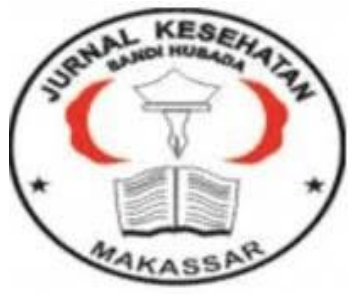

\author{
Jurnal Ilmiah Kesehatan Sandi Husada \\ hhttps://akper-sandikarsa.e-journal.id/JIKSH \\ Vol 9, No, 1, Juni 2020, pp;30-36 \\ p-ISSN: 2354-6093 dan e-ISSN: 2654-4563 \\ DOI: $10.35816 /$ jiskh.v10i2.214
}

\title{
ARTIKEL PENELITIAN Hubungan Merokok Dan Riwayat Keturunan Dengan Kejadian Hipertensi
}

\author{
Relationship between Smoking and Hereditary History with Hypertension
}

\author{
Nanang dismiantoni' ${ }^{1}$, Anggunan² ${ }^{2}$, Nia triswanti ${ }^{3}$, Rina Kriswiastiny ${ }^{4}$ \\ 1Program Studi Kedokteran Fakultas Kedokteran Universitas Malahayati \\ ${ }^{2}$ Departemen imunologi Fakultas Kedokteran Universitas Malahayati \\ ${ }^{3}$ Departemen biokimia Fakultas Kedokteran Universitas Malahayati \\ ${ }^{4}$ Departemen Interna Rumah Sakit Pertamina Bintang Amin
}

\begin{tabular}{l}
\hline \multicolumn{1}{c}{ Artikel info } \\
\hline Artikel history: \\
Received; 08 Maret 2020 \\
Revised; 11 Maret 2020 \\
Accepted; 12 Maret 2020
\end{tabular}

Nanang dismiantoni, etall, Relationship Between Smoking and Hereditary History With Hypertension, JIKSH Vol. 9 No.1 Juni 2019

\begin{abstract}
Abstrak
Latar Belakang: Merokok merupakan overt behavior dimana perokok menghisap gulungan tembakau. Dalam hal ini dimaksud bahwa merokok adalah menghisap gulungan tembakau yang dibungkus dengan kertas. Riwayat keturunan adalah apabila kedua orang tua memiliki riwayat penyakit maka keturunannya akan beresiko terkena penyakit tersebut karena pengaruh genetika. Hipertensi merupakan keadaan ketika tekanan darah sistolik $\geq 140 \mathrm{mmHg}$ dan diastolik $\geq 90 \mathrm{mmHg}$ pada dua kali pemeriksaan pengukuran tekanan darah dalam jangka waktu 5 menit dalam keadaan rileks. Metodologi: Jenis penelitian yang digunakan adalah metode analitik observasional dengan pendekatan cross-sectional menggunakan kuisioner. Populasi penelitian ini adalah seluruh pasien yang di curigai hipertensi di wilayah kerja puskesmas simbarwaringin kecamatan trimurjo lampung tengah tahun 2019, serta pengambilan sampel menggunakan metode purposive sampling, dengan jumlah sample sebanyak 88. Data dianalisis dengan Uji Chi-Square. Hasil: Pada penelitian ini didapatkan dari 42 responden yang memiliki kebiasaan merokok, sebagian besar mengalami kejadian hipertensi sebanyak 36 orang (85.7\%). Sama halnya juga dari 59 responden yang memiliki faktor keturunan, sebagian besar mengalami kejadian hipertensi sebanyak 48 orang (81.4\%). Dengan menggunakan uji Chi Square menunjukkan p-value $=0.016$ dimana kurang dari nilai kemaknaan yaitu 5\% (0.05), hal tersebut menunjukkan terdapat hubungan yang signifikan antara kebiasaan merokok dengan kejadian hipertensi dan juga terdapat hubungan faktor keturunan dengan kejadian hipertensi Dengan menggunakan uji Chi Square menunjukkan p-value $=0.023$ dimana kurang dari nilai kemaknaan yaitu 5\% (0.05). Kesimpulan: Ada hubungan antara merokok dan riwayat keturunan terhadap kejadian hipertensi di wilayah kerja puskesmas simbarwaringin kecamatan trimurjo lampung tengah tahun 2019.
\end{abstract}




\begin{abstract}
Background: Smoking is an overt behavior in which smokers inhale tobacco rolls. In this case, it means that smoking is inhaling a roll of tobacco that wrapped in a paper. History of descent is if both parents have a history of the disease, then their descent will be at risk for getting the disease because of the genetics influence. Hypertension is a condition when the systolic blood pressure $\geq 140 \mathrm{mmHg}$ and diastolic $\geq 90 \mathrm{mmHg}$ on two blood pressure measurement examinations within 5 minutes and in a relaxed state. Methodology: The type of research that is used is patients that are suspected of having hypertension in the working area of Community Health Center (PUSKESMAS observational analytic method with cross-sectional approach by using a questionnaire. The population of this study was all) Simbarwaringin in Trimurjo district of Central Lampung in 2019. As well as sampling using purposive sampling method, with a total of 88 samples. The data were analyzed by Chi-Square test. Result: In this study, out of 42 respondents who have a smoking habit, most experienced hypertension as many as 36 people (85.7\%). Similarly of the 59 respondents who have hereditary factors, most experienced hypertension as many as 48 people $(81.4 \%)$. By using the Chi-Square test, shows that a p-value = 0.016 which is less than the value of significance of $5 \%$. It shows a significant relationship between smoking habit with the incidence of hypertension and also a relationship of hereditary with the incidence of hypertension by using Chi-Square showed a $p$-value $=0.023$ which is less than the value of significance of $5 \%$ (0.05). Conclusion: There is a relationship between smoking and the history of descent with hypertension events in the working area of Community Health Center (PUSKESMAS) Simbarwaringin in Trimurjo district of Central Lampung in 2019.
\end{abstract}

Keywords:

Merokok;

Riwayat keturunan;

Hipertens;
Coresponden author:

Email:ndesmiantomi@gmail.com

artikel dengan akses terbuka dibawah lisensi CC BY -4.0

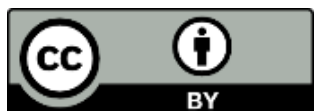

\title{
PENDAHULUAN
}

Hipertensi merupakan keadaan ketika tekanan darah sistolik $\geq 140 \mathrm{mmHg}$ dan tekanan diastolic $\geq 90 \mathrm{mmHg}$ pada dua kali pemeriksaan pengukuran tekanan darah dalam jangka waktu 5 menit dengan keadaan relaks. Pada umumnya pasien hipertensi tidak merasakan keluhan dan gejala yang khas sehingga banyak penderita yang tidak menyadari bahwa menderita hipertensi (Ningsih, 2017). Berdasarkan data dari Riskesdas 2018 menunjukkan bahwa prevalensi penyakit tidak menular mengalami peningkatan jika dibandingkan dengan data Riskesdas pada tahun 2013. Hipertensi, diabetes melitus, kanker, stroke, penyakit ginjal kronis adalah contoh penyakit tidak menular yang mengalami peningkatan setiap tahunya. Dijelaskan oleh kepala Badan penelitian dan pengembangan kesehatan, Siswanto, berdasarkan hasil pengukuran tekanan darah, 
jumlah hipertensi naik dari 25,8 persen menjadi 34,1 persen, prevalensi stroke naik dari 7 persen menjadi 10,9 persen, prevalensi diabetes melitus naik dari 6,9 persen menjadi 8,5 persen. Begitu pula dengan prevalensi kanker naik dari 1,4 persen menjadi 1,8 persen, dan penyakit ginjal kronik naik dari 2 persen menjadi 3,8 persen di tahun 2018 (Kementerian Kesehatan \& Indonesia, 2019).

Di Puskesmas Simbawaringin Kecamatan Trimurjo Lampung Tengah, dari data yang ada pasien hipertensi menduduki urutan ke dua dari penyakit yang sering ditemukan. Jumlah pasien hipertensi dari tahun 2017 sampai 2018 mengalami peningkatan, dengan jumlah pasien hipertensi tahun 2017 sebnanyak 1.065 pasien dan tahun 2018 menjadi 1.174 pasien. Dari data tersebut dapat disumpulkan bahwa pasien hipertensi mengalami peningkatan setiap tahunnya.

Kenaikan pravelensi hipertensi karena hipertensi dapat terjadi dengan dipengaruhi oleh gaya hidup dan asupan makanan. Faktor-faktor yang dapat mempengaruhi hipertensi dibagi menjadi dua kelompok yaitu faktor yang tidak dapat dikendalikan seperti usia, jenis kelamin, genetik, ras, dan faktor yang dapat dikendalikan seperti pola makan, kebiasaan merokok, asupan garam yang berlebihan, aktivitas fisik yang kurang, gaya hidup, pola tidur, dan stres emosional. Hasil penelitian Mannan dkk (2012), menunjukkan bahwa riwayat keluarga, aktivitas fisik, perilaku merokok, dan konsumsi garam merupakan faktor risiko kejadian hipertensi (Dedullah et al., 2015).Merokok adalah kebiasaan menghisap gulungan tembakau.

\section{Metode}

Penelitian ini dilakukan di wilayah kerja puskesmas simbarwaringin kecamatan trimurjo lampung tengah pada bulan desember 2019 sampai januari 2020.Penelitian ini termasuk dalam jenis penelitian analitik observational dengan metode cross sectional dan data diambil dengan data primer (kuesioer).

Kriteria inklusi pada penelitian ini, yaitu: Pasien yang yang datang berobat ke puskesmas simbawaringin kecamatan trimurjo lampung tengah, Pasien yang memiliki usia 30 tahun hingga 70 tahun dating berobat ke puskesmas simbawaringin kecamatan trimurjo lampung tengah,Pasien yang datang berobat ke puskesmas simbawaringin minimal 2 kali pemeriksaan tekanan darah dengan jarak yang berbeda dalam keadaan tekanan darah lebih dari 140/90 mmHg, Bisa membaca dan berkomunikasi dengan baik dan benar, Pasien hipertensi yang bersedia menandatangani informed consent dan mengisi kuisioner

Kriteria ekslusi pada penelitian ini, yaitu : Pasien hipertensi datang ke puskesmas dengan keadaan tidak sadarkan diri. Pasien hipertensi sekunder.Data sampel adalah sebagian populasi yaitu pasien dengan hipertensi di wilayah kerja Puskesmas Simbarwaringin Kecamatan Trimurjo Lampung Tengah tahun 2019 yang memenuhi kriteria inklusi.Maka besar sampel ditentukan dengan menggunakan metode purposive sampling dihitung dengan menggunakan rumus slovin sebanyak 88 orang. 


\section{Hasil Dan Pembahasan}

Table 6. Analisis Hubungan Kebiasaan Merokok Dengan Kejadian Hipertensi di Puskesmas Simbarwaringin kecamatan Trimurjo, Kabupaten Lampung Tengah, provinsi Lampung tahun 2019

\begin{tabular}{|c|c|c|c|c|c|c|c|c|}
\hline \multirow{3}{*}{$\begin{array}{l}\text { Kebiasaan } \\
\text { Merokok }\end{array}$} & \multicolumn{4}{|c|}{ Kejadian Hipertensi } & \multirow{3}{*}{ Total } & \multirow{3}{*}{$\%$} & \multirow{3}{*}{$\begin{array}{l}\text { p- } \\
\text { valu } \\
e\end{array}$} & \multirow{3}{*}{$\begin{array}{l}\text { OR } \\
\text { (CI95\%) }\end{array}$} \\
\hline & \multicolumn{2}{|c|}{$\begin{array}{l}\text { Tidak } \\
\text { Hipertensi }\end{array}$} & \multicolumn{2}{|c|}{ Hipertensi } & & & & \\
\hline & $\mathrm{n}$ & $\%$ & $\mathrm{~N}$ & $\%$ & & & & \\
\hline $\begin{array}{l}\text { Tidak } \\
\text { merokok }\end{array}$ & 17 & 37.0 & 29 & 63.0 & 46 & $\begin{array}{l}10 \\
0\end{array}$ & & \\
\hline Merokok & 6 & 14.3 & 36 & 85.7 & 42 & $\begin{array}{l}10 \\
0\end{array}$ & $\begin{array}{l}0.01 \\
6\end{array}$ & $\begin{array}{l}3.51(1.22 \\
-10.06)\end{array}$ \\
\hline Total & 23 & 26.1 & 65 & 73.9 & 88 & $\begin{array}{l}10 \\
0\end{array}$ & & \\
\hline
\end{tabular}

Dengan menggunakan uji statistik analisis bivariat diketahui dari 42 responden yang memiliki kebiasaan merokok, sebagian besar mengalami kejadian hipertensi sebanyak 36 orang (85.7\%). Sama halnya dari 46 responden yang tidak memiliki kebiasaan merokok, sebagian besar mengalami kejadian hipertensi sebanyak 29 orang (63.0\%). Dengan menggunakan uji Chi Square menunjukkan p-value $=0.016$ dimana kurang dari nilai kemaknaan yaitu 5\% (0.05), hal tersebut menunjukkan terdapat hubungan yang signifikan antara kebiasaan merokok dengan kejadian hipertensi. Dari analisis di atas didapatkan nilai $\mathrm{OR}=3.51$ yang menunjukkan bahwa kebiasaan merokok responden berisiko 3.51 kali untuk mengalami kejadian hipertensi.

Table 7. Analisis Hubungan Faktor Keturunan Dengan Kejadian Hipertensi di Puskesmas Simbarwaringin kecamatan Trimurjo, Kabupaten Lampung Tengah, provinsi Lampung tahun 2019

\begin{tabular}{|c|c|c|c|c|c|c|c|c|}
\hline \multirow{3}{*}{$\begin{array}{l}\text { Faktor } \\
\text { Keturuna } \\
\text { n }\end{array}$} & \multicolumn{4}{|c|}{ Kejadian Hipertensi } & \multirow{3}{*}{$\begin{array}{l}\text { Tota } \\
1\end{array}$} & \multirow{3}{*}{$\%$} & \multirow{3}{*}{$\begin{array}{l}\text { p- } \\
\text { valu } \\
e\end{array}$} & \multirow{3}{*}{$\begin{array}{l}\text { OR } \\
\text { (CI95\%) }\end{array}$} \\
\hline & \multicolumn{2}{|c|}{$\begin{array}{l}\text { Tidak } \\
\text { Hipertensi }\end{array}$} & \multicolumn{2}{|c|}{ Hipertensi } & & & & \\
\hline & $\mathrm{n}$ & $\%$ & $\mathrm{~N}$ & $\%$ & & & & \\
\hline Tidak ada & 12 & 41.4 & 17 & 58.6 & 29 & $\begin{array}{l}10 \\
0\end{array}$ & & \\
\hline Ada & 11 & 18.6 & 48 & 81.4 & 59 & $\begin{array}{l}10 \\
0\end{array}$ & $\begin{array}{l}0.02 \\
3\end{array}$ & $\begin{array}{l}3.08(1 \\
.14- \\
8.27)\end{array}$ \\
\hline Total & 23 & 26.1 & 65 & 73.9 & 88 & $\begin{array}{l}10 \\
0\end{array}$ & & \\
\hline
\end{tabular}

Dengan menggunakan uji statistik analisis bivariat diketahui dari 29 responden yang tidak memiliki faktor keturunan sabagian besar mengalami kejadian hipertensi sebanyak 17 orang (58.6\%). Sama halnya juga dari 59 responden yang memiliki faktor keturunan, sebagian besar mengalami kejadian hipertensi sebanyak 48 orang (81.4\%). Dengan

Nanang dismiantoni, etall, Relationship Between Smoking and Hereditary History With Hypertension, JIKSH Vol. 9 No.1 Juni 2019 
menggunakan uji Chi Square menunjukkan p-value $=0.023$ dimana kurang dari nilai kemaknaan yaitu 5\% (0.05), hal tersebut menunjukkan terdapat hubungan yang signifikan antara faktor keturunan dengan kejadian hipertensi. Dari analisis di atas didapatkan nilai $\mathrm{OR}=3.08$ yang menunjukkan bahwa faktor keturunan responden berisiko 3.08 kali untuk mengalami kejadian hipertensi.]

\section{PEMBAHASAN}

1. Hubungan Kebiasaan Merokok Dengan Kejadian Hipertensi di Puskesmas Simbarwaringin kecamatan Trimurjo, Kabupaten Lampung Tengah, provinsi Lampung tahun 2019

Hasil penelitian sejalan dengan penelitian Lailatun (2013) pada masyarakat di wilayah kerja Puskesmas Rumbai Pesisir dimana terdapat hubungan yang bermakna secara statistik antara kebiasaan merokok dengan penyebab hipertensi dengan diperoleh nilai p-value $=0.006$. Faktor - faktor pencetus kejadian hipertensi semakin berkembang seiring dengan perkembangan zaman. Berdasarkan hasil observasi yang dilakukan, peneliti melihat adanya kecenderungan perubahan pola gaya hidup di masyarakat saat ini. Prilaku merokok kini juga bukan hanya dilakukan oleh orang dewasa tetapi juga oleh remaja. Kebiasaan merokok berperan menyebabkan terjadinya hipertensi karena rokok mengandung nikotin dan karbon monoksida yang berpengaruh terhadap tekanan darah. Nikotin dapat meningkatkan asam lemak, mengaktivasi trombosit, memicu aterosklerosis dan penyempitan pembuluh darah (Anggie, 2012) Sedangkan karbon monoksida mengakibatkan hemoglobin dalam darah rusak sehingga menumpuk di membrane pembuluh kapilier dan menyebabkan penebalam dinding pembuluh darah (Rakhmawati 2013)

\section{Hubungan Faktor Keturunan Dengan Kejadian Hipertensi di Puskesmas Simbarwaringin kecamatan Trimurjo, Kabupaten Lampung Tengah, provinsi Lampung tahun 2019}

Hasil penelitian sejalan dengan (Raihan \& Dewi, 2009) pada masyarakat di wilayah kerja Puskesmas Rumbai Pesisir dimana terdapat hubungan yang bermakna secara statistik antara kebiasaan merokok dengan penyebab hipertensi dengan diperoleh nilai $\mathrm{p}$-value $=0.000$. Riwayat keluarga dan faktor genetik remaja yang berasal dari keluarga dengan riwayat hipertensi, mempunyai risiko yang lebih besar untuk menderita hipertensi dibanding dengan keluarga tanpa riwayat hipertensi. Jika kedua orangtua hipertensi, maka angka kejadian hipertensi pada keturunannya meningkat 4 sampai 15 kali dibanding bila kedua orangtua adalah normotensi. Bila kedua orangtua menderita hipertensi esensial, maka 44,8\% anaknya akan menderita hipertensi. Jika hanya salah satu orangtua hipertensi maka 12,8\% keturunannya akan mengalami hipertensi. Ekspresi dari hipertensi pada seseorang sepertinya merupakan hasil dari perubahan-perubahan pada genetik. Telah terbukti bahwa bukan hanya tekanan darah, tapi juga mekanisme pengaturan sistem reninangiotensin-aldosteron, sistem saraf simpatis, semuanya dipengaruhi secara genetik. Teknik biomolekular modern telah memungkinkan pemeriksaan gen yang bertanggungjawab terhadap terjadinya hipertensi pada seseorang (Saing, 2016).. 


\section{Simpulan Dan Saran}

Berdasarkan analisis data hasil penelitian mengenai hubungan kebiasaan merokok dan faktor keturunan dengan kejadian hipertensi di Puskesmas Simbarwaringin kecamatan Trimurjo, Kabupaten Lampung Tengah, Provinsi Lampung. Tahun 2019 diperoleh kesimpulan sebagai berikut :

1. Sebagian besar responden tidak perokok sebanyak 46 orang (52.3\%).

2. Sebagian besar responden memiliki faktor keturunan hipertensi sebanyak 59 orang $(67.0 \%)$.

3. Sebagian besar responden mengalami hipertensi sebanyak 65 orang $(73.9 \%)$

4. Terdapat hubungan yang signifikan antara kebiasaan merokok dengan kejadian hipertensi ( $p$-value=0.016). Dari analisis di atas didapatkan nilai OR $=3.51$ yang menunjukkan bahwa kebiasaan merokok responden berisiko 3.51 kali untuk mengalami kejadian hipertensi.

5. Terdapat hubungan yang signifikan antara faktor keturunan dengan kejadian hipertensi ( $p$-value $=0.023$ ). Dari analisis di atas didapatkan nilai OR $=3.08$ yang menunjukkan bahwa faktor keturunan responden berisiko 3.08 kali untuk mengalami kejadian hipertensi.

Hasil penelitian ini dapat digunakan sebagai informasi atau penyuluhan mengenai hipertensi primer, faktor-faktor penyebab, dan cara mencegah melalui perubahan gaya hidup ke arah yang lebih baik. Selain itu, dapat diaplikasikan oleh responden dan keluarga dalam membantu menurunkan tekanan darah secara efisien dan efektif dengan menghindari faktor-faktor yang dapat diubah.

Penderita hipertensi agar lebih memperhatikan faktor-faktor yang dapat meningkatkan derajat keparahan hipertensi dan lebih mengatur pola hidup yang baik serta melakukan chek-up secara berkala di Puskesmas..

\section{Daftar Rujukan}

Dedullah, R. F., Malonda, N. S. H., \& Joseph, W. B. S. (2015). Hubungan antara faktor risiko hipertensi dengan kejadian hipertensi pada masyarakat di Kelurahan Motoboi Kecil Kecamatan Kotamobagu Selatan Kota Kotamobagu. Jurnal Kesmas, 4(2), 111-118.

Kementerian Kesehatan, \& Indonesia, R. (2019). Hipertensi Penyakit Paling Banyak Diidap Masyarakat. Kementerian Kesehatan RI. Sekretariat r Jenderal. Rencana Strategis Kementerian Kesehatan Tahun Rencana Strategis Kementerian Kesehatan Tahun, 248. https://doi.org/351.077 Ind $\mathrm{r}$

Ningsih, D. L. R. (2017). Faktor-faktor yang berhubungan dengan kejadian hipertensi pada pekerja sektor informal di pasar beringharjo kota yogyakarta. Naskah Publikasi, 1-20. https://doi.org/http://dx.doi.org/10.1016/j.brainres.2009.04.039

Raihan, L. N., \& Dewi, A. P. (2009). Faktor-faktor Yang Berhubungan Dengan Kejadian Hipertensi Primer Pada Mayarakat Di Wilayah Kerja Puskesmas Rumbai Pesisir. JOM PSIK Vol 1 No 2, 1, 1-10.

Saing, J. H. (2016). Hipertensi pada Remaja. Sari Pediatri, 6(4), 159. https://doi.org/10.14238/sp6.4.2005.159-65

Artiyaningrum, B. (2001). Faktor-faktor yang berhubungan dengan kejadian hipertensi tidak terkendali pada penderita yang melakukan pemeriksaan rutin di puskesmas kedungmundu kota semarang tahun 2014 (Doctoral dissertation, UNIVERSITAS 
NEGERI SEMARANG).

Harahap, M. T. Tingkat Pengetahuan dan Tindakan Mahasiswa Fakultas Kedokteran Universitas Sumatera Utara Terhadap Penanganan Pasien Hipertensi di Lingkungan Keluarga Guna Mengurangi Faktor Risiko Terjadinya Stroke.

Azhari, M. H. (2017). Faktor-faktor yang berhubungan dengan kejadian hipertensi di Puskesmas Makrayu Kecamatan Ilir Barat II Palembang. Jurnal Aisyah: Jurnal Ilmu Kesehatan, 2(1), 23-30.

Irza, S. (2009). Analisis Faktor Risiko Hipertensi Pada Masyarakat Nagari Bungo Tanjung, Sumatera Barat.

Anggara, F. H. D., \& Prayitno, N. (2013). Faktor-faktor yang berhubungan dengan tekanan darah di Puskesmas Telaga Murni, Cikarang Barat tahun 2012. Jurnal Ilmiah Kesehatan, 5(1), 20-25.

Hanifa, A. (2009). Prevalensi Hipertensi Sebagai Penyebab Penyakit Ginjal Kronik Di Unit Hemodialisis RSUP H. Adam Malik Medan Tahun 2009.

Astuti, D. D., Prasetyowati, I., \& Wahjudi, P. Merokok: Hipertensi pada Kelompok Usia 1544 Tahun.

Thuy, A. B., Blizzard, L., Schmidt, M. D., Luc, P. H., Granger, R. H., \& Dwyer, T. (2010). The association between smoking and hypertension in a population-based sample of Vietnamese men. Journal of hypertension, 28(2), 245-250.

Rakhmawati, S., Chasani, S., \& SANTOSO, S. (2013). Hubungan Antara Derajat Hipertensi Pada Pasien Usia Lanjut Dengan Komplikasi Organ Target Di Rsup Dokter Kariadi Semarang Periode 2008-2012 (Doctoral dissertation, Faculty of Medicine University Diponegoro). 